\title{
Cardiac Impulse in Hypertrophic Obstructive Cardiomyopathy
}

\author{
R. E. NAGLE, O. W. BOICOURT, P. M. S. GILlAM, AND J. P. D. MOUNSEY \\ From the Department of Medicine and the M.R.C. Cardiovascular Group, Postgraduate Medical School, \\ Hammersmith Hospital, London W.12
}

A double apical impulse has been described as a physical sign in hypertrophic obstructive cardiomyopathy (Mounsey, 1959; Braunwald et al., 1960; Boiteau and Allenstein, 1961; Paré et al., 1961; Benchimol, Legler, and Dimond, 1963; Cohen et al., 1964; Gillam, Deliyannis, and Mounsey, 1964; Tafur, Cohen, and Levine, 1964). In this study we have used the impulse cardiogram, which is an optical record of what the hand feels, to determine more exactly the nature of these abnormalities of the cardiac impulse. Our object has been to assess the clinical significance of the different forms of cardiac impulse in this disease, relating them to the underlying hæmodynamic disturbances.

\section{The INVESTigation}

Studies were carried out on 14 patients with hypertrophic obstructive cardiomyopathy. The clinical diagnosis, supported by radiological and electrocardiographic evidence of ventricular, and often atrial, hypertrophy, was confirmed at cardiac catheterization and angiocardiography. A pressure gradient across the outflow tract of the left, or both right and left, ventricles was demonstrated, which varied with different physiological and pharmacological manœuvres. The configuration of the cavity of the left ventricle was shown on angiocardiography to be characteristic of hypertrophic obstructive cardiomyopathy, with gross regional thickening of the ventricular wall and a functional form of stenosis in the outflow tract during systole.

In every patient the cardiac impulse was recorded at the apex and at the left sternal edge by means of the impulse cardiograph (Beilin and Mounsey, 1962) which records displacement of the chest wall relative to a fixed point in space. It was calibrated in this study so that movement of the chest wall of $1 \mathrm{~mm}$. produced a deflection in the record of $60 \mathrm{~mm}$. Records were made with the patient lying supine propped up at an angle of about

Received October 4, 1965.

2E
45 degrees. They were taken when the breath was held at the end of quiet expiration and a simultaneous electrocardiogram and phonocardiogram were recorded $\mathrm{j}_{\mathrm{j}}$ as reference tracings. In every patient the form of the impulse cardiogram corresponded closely to the clinical impression on palpation of the præcordium.

Retrograde left ventricular catheterization was performed in all of the patients. In addition, in 9 patients in whom right heart involvement was suspected, right heart catheterization was also performed. Bi-plane angiocardiograms, using an Elema roll-film changer, and also one-plane cine-angiocardiograms were taken during the same investigation.

The pressure records thus obtained were available for detailed study. Pressure gradients between the left ventricular cavity and the aorta were measured. Where right heart catheterization had been performed, any pressure gradient between the right ventricle and the pulmonary artery was noted. Three moments in diastole were selected for pressure measurement: diastasis (or the period immediately preceding atrial systole); atrial systole, when the height of the " $a$ " wave was measured; and end-diastole, between the "a" wave and the beginning of ventricular systole. These measurements were selected as affording evidence of increased force of atrial contraction and of diminished compliance of the ventricle.

In order to gain an impression of changes in cavity volume throughout the cardiac cycle, three of the cineangiocardiograms were selected for detailed analysis and sequential changes in ventricular cross-sectional area were measured. The three cine-angiocardiograms selected were free from ventricular ectopic beats, tachycardia, or technical imperfections which made the other cine-angiocardiograms unsuitable for detailed study. The cine-films were taken at a speed of about 40 frames a second, the exact speed in each run being arrived at by dividing the number of exposed frames into the duration of $\mathrm{x}$-ray exposure, which was recorded alongside a simultaneous electrocardiogram. Individual frames could thus be accurately related to the electrocardiogram and, in a more general way, to hæmodynamic 419 


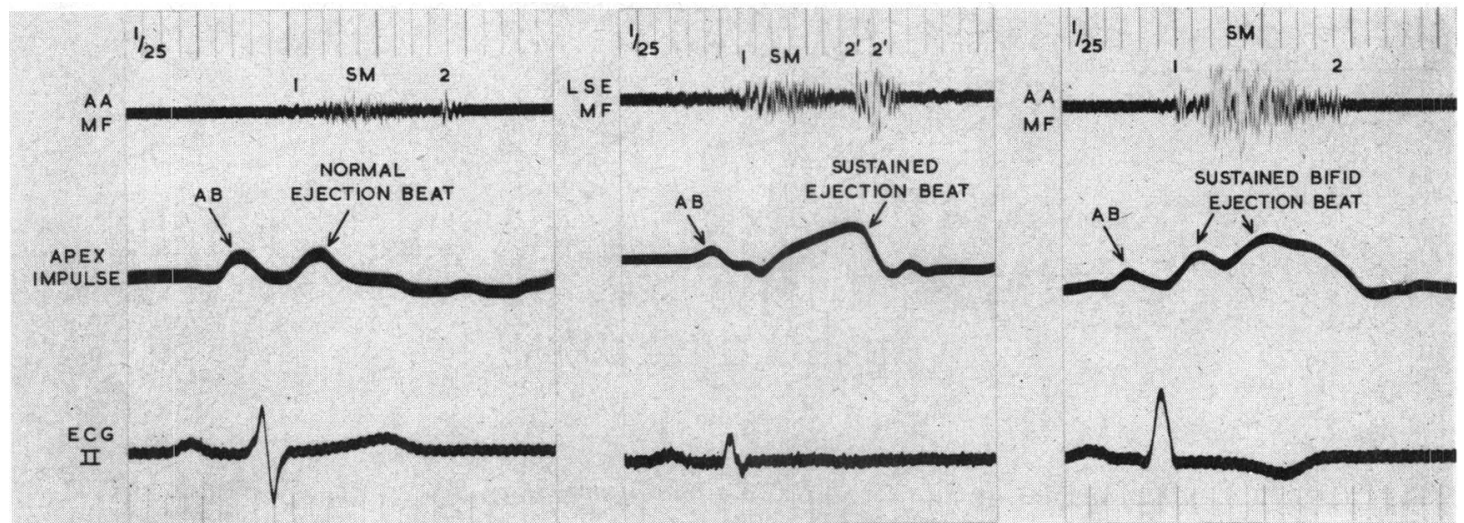

(a)

(b)

(c)

FIG. 1.-Three types of abnormal apical impulse in "cardiomyopathy. (a) Large atrial beat (AB) and normal ventricular systolic impulse. (b) Moderately large atrial beat and sustained ventricular systolic impulse. (c) Moderately large atrial beat and bifid sustained ventricular systolic impulse.

Phonocardiograms: $A A=$ aortic area; $L S E=$ left sternal edge; $M F=$ medium frequency; $S M=$ systolic murmur; 1 and 2 = first and second heart sounds. Electrocardiogram lead II.

electrocardiogram being used to link the two. For sequential analysis, the film was projected onto a screen and the outlines of the cavities of the ventricle and atrium traced onto celluloid. The cross-sectional areas of the cavities were determined by planimetry.

\section{RESULTS}

Apical Impulse. A cardiac impulse at the apex with two or more major deflections was recorded in 13 of the 14 patients studied. In 10 of these patients the double nature of the impulse was due to a large atrial beat accompanying atrial systole and preceding the ventricular systolic impulse (Fig. 1) (Beilin and
Mounsey, 1962). In the other 3 patients the ventricular systolic impulse itself was bifid, and, since it was preceded by a large atrial beat, the cardiac impulse showed three major outward deflections (Fig. 1c).

Impulse during ventricular systole. Detailed analysis of the ventricular systolic portion of the apical impulse showed this to be normal in form in 4 patients (Beilin and Mounsey, 1962) (Fig. 1a). In the remaining 10 patients, it was abnormally sustained at the apex (Beilin and Mounsey, 1962) (Fig. 1b). In addition in 3 of these 10 patients the

TABLE

APEX IMPULSE AND HEMODYNAMIC CORRELATIONS IN 14 PATIENTS WITH OBSTRUCTIVE CARDIOMYOPATHY

\begin{tabular}{|c|c|c|c|c|c|c|c|c|c|c|}
\hline \multirow{2}{*}{\multicolumn{3}{|c|}{ Case No., sex, and age (yr.) }} & \multirow[t]{2}{*}{$\begin{array}{c}\text { Left ventr. } \\
\text { syst. } \\
\text { gradient } \\
\text { (mm. Hg) }\end{array}$} & \multirow[t]{2}{*}{$\underset{\text { (apex) }}{\text { Ventricular impulse }}$} & \multirow[t]{2}{*}{$\underset{\substack{\text { impulse } \\
\text { (apex) }}}{\text { Atrial }}$} & \multirow[t]{2}{*}{$\begin{array}{c}\text { Height } \\
\text { of atrial } \\
\text { impulse } \\
(\mathrm{mm} .)\end{array}$} & \multirow[t]{2}{*}{$\begin{array}{l}\text { Atrio-ventricular } \\
\text { impulse ratio }\end{array}$} & \multicolumn{3}{|c|}{$\begin{array}{l}\text { Left ventr. } \\
\text { diast. pressure } \\
(\mathrm{mm} . \mathrm{Hg})\end{array}$} \\
\hline & & & & & & & & 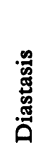 & 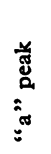 & 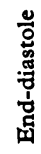 \\
\hline $\begin{array}{r}15 \\
16 \\
9 \\
13 \\
17 \\
8 \\
6 \\
11 \\
2 \\
3 \\
18 \\
7 \\
14 \\
1\end{array}$ & $\begin{array}{l}\mathbf{M} \\
\mathbf{F} \\
\mathbf{M} \\
\mathbf{M} \\
\mathbf{F} \\
\mathbf{F} \\
\mathbf{M} \\
\mathbf{F} \\
\mathbf{M} \\
\mathbf{F} \\
\mathbf{M} \\
\mathbf{F} \\
\mathbf{M}\end{array}$ & $\begin{array}{l}25 \\
18 \\
30 \\
30 \\
36 \\
52 \\
39 \\
17 \\
45 \\
43 \\
45 \\
33 \\
52 \\
13\end{array}$ & $\begin{array}{r}100 \\
100 \\
81 \\
80 \\
75 \\
63 \\
60 \\
56 \\
50 \\
50 \\
40 \\
30 \\
10 \\
10\end{array}$ & $\begin{array}{l}\text { Sustained (bifid) } \\
\text { Sustained } \\
\text { Sustained } \\
\text { Sustained (bifid) } \\
\text { Sustained (bifid) } \\
\text { Sustained } \\
\text { Normal } \\
\text { Normal } \\
\text { Sustained } \\
\text { Normal } \\
\text { Normal } \\
\text { Sustained } \\
\text { Sustained } \\
\text { Sustained }\end{array}$ & $\begin{array}{l}\text { Moderate } \\
\text { Moderate } \\
\text { Large } \\
\text { Giant } \\
\text { Giant } \\
\quad 0 \\
\text { Large } \\
\text { Giant } \\
\text { Giant } \\
\text { Giant } \\
\text { Large } \\
\text { Moderate } \\
\text { Moderate } \\
\text { Giant }\end{array}$ & $\begin{array}{r}3 \\
4 \\
6 \\
14 \\
25 \\
0 \\
5 \\
12 \\
18 \\
12 \\
8 \\
3 \\
2 \\
15\end{array}$ & $\begin{array}{l}0.25 \\
0.4 \\
0.2 \\
1.5 \\
0.8 \\
0 \\
0 \cdot 8 \\
0.9 \\
0.9 \\
0.9 \\
0.4 \\
0.4 \\
0.1 \\
1.25\end{array}$ & $\begin{array}{r}5 \\
5 \\
12 \\
0 \\
0 \\
0 \\
5 \\
1 \\
0 \\
7 \\
3 \\
8 \\
0 \\
0\end{array}$ & $\begin{array}{l}38 \\
35 \\
38 \\
55 \\
24 \\
20 \\
15 \\
47 \\
25 \\
32 \\
17 \\
21 \\
15 \\
20\end{array}$ & $\begin{array}{r}18 \\
20 \\
18 \\
15 \\
9 \\
12 \\
13 \\
21 \\
12 \\
13 \\
9 \\
17 \\
5 \\
8\end{array}$ \\
\hline
\end{tabular}


sustained impulse had a bifid character, showing 2 distinct humps during ventricular systole (Fig. 1c).

Hamodynamic correlations. A sustained apical impulse has been shown to be associated closely with the development of left ventricular hypertrophy (Beilin and Mounsey, 1962; Deliyannis et al., 1964). Some correlation, therefore, might be expected between the systolic gradient across the left ventricular outflow tract in patients with hypertrophic obstructive cardiomyopathy and the nature of the apical impulse. In the Table it will be seen that all patients having a gradient of more than $60 \mathrm{~mm}$. $\mathrm{Hg}$ showed a sustained impulse. In the remaining 8 patients with smaller gradients at the time of catheterization the type of impulse was variable, 3 of the patients with the smallest gradients showing conspicuously abnormal impulses.

Giant Atrial Beat. It was in the portion of the cardiac impulse during atrial systole that the physical sign most suggestive of the diagnosis of hypertrophic obstructive cardiomyopathy was usually seen.

A small atrial beat at the apex, measuring 1 to $2 \mathrm{~mm}$. in the impulse cardiogram, is sometimes seen in health but is seldom easily palpable (Beilin and Mounsey, 1962). In left ventricular hypertrophy from hypertension or aortic stenosis, an augmented atrial beat of 5 to $10 \mathrm{~mm}$. is commonly seen and felt. In our series of patients with cardiomyopathy, however, outstandingly large "giant" atrial beats were common. Thus in 6 patients they were more than $10 \mathrm{~mm}$. in height, approaching and, in two cases, exceeding the height of the ventricular systolic impulse (Fig. 2a). Two of these giant atrial beats were followed by a ventricular systolic impulse of normal configuration. Seven patients had moderate-sized atrial beats of between 2 and $8 \mathrm{~mm}$. in height: in 5 they were associated with a sustained ventricular beat, while in 2 they were followed by a ventricular beat of normal form. Only one patient had no atrial beat, but in him the ventricular beat was abnormally sustained.

Hamodynamic correlations. The frequency of a large atrial beat in the cardiac impulse of our patients reflected the underlying hæmodynamic disturbances. There is good evidence that decreased compliance of the ventricles and increased atrial systolic pressure are important hæmodynamic abnormalities in hypertrophic obstructive cardiomyopathy (Braunwald and Ebert, 1962; Wigle, Heimbecker and Gunton, 1962; Cohen et al., 1964; Gillam et al., 1964). In order to gain some idea of the extent of the disturbances of ventricular filling in these patients, measurements of the left ventricular pressure at three moments during diastole were made as described above. In the Table it will be seen that, with one exception, the pressure was not raised during diastasis, immediately before atrial contraction. During atrial systole, however, very high pressures were recorded, the peak of the "a" wave reaching $55 \mathrm{~mm}$. $\mathrm{Hg}$ in Case 13. Equally abnormal was the height of the end-diastolic pressure which, with one exception, was always raised. These figures, therefore, gave confirmation both of the increased force of left atrial contraction and of decreased compliance of the left ventricle in end-diastole.

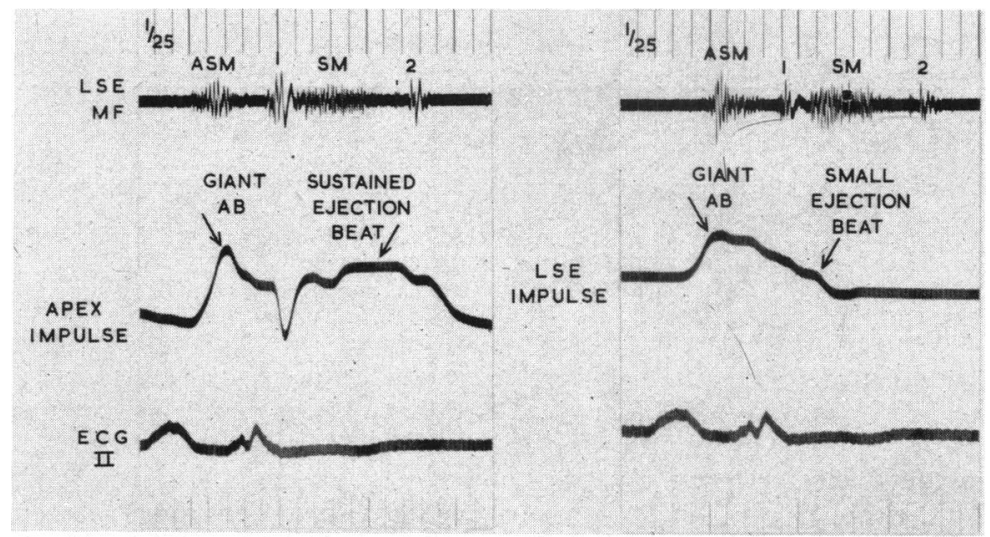

(a)

(b)

FIG. 2.-Giant atrial beat (AB) in cardiomyopathy, exceeding in amplitude the ventricular systolic impulse (Case 1). (a) Apical impulse. (b) Left parasternal impulse.

Phonocardiogram at left sternal edge (LSE); medium frequency (MF); ASM=atrial systolic murmur. 1 and 2 = first and second heart sounds; $S M=$ systolic murmur. Electrocardiogram lead II. 


\section{CAVITY AREA}

sq. units
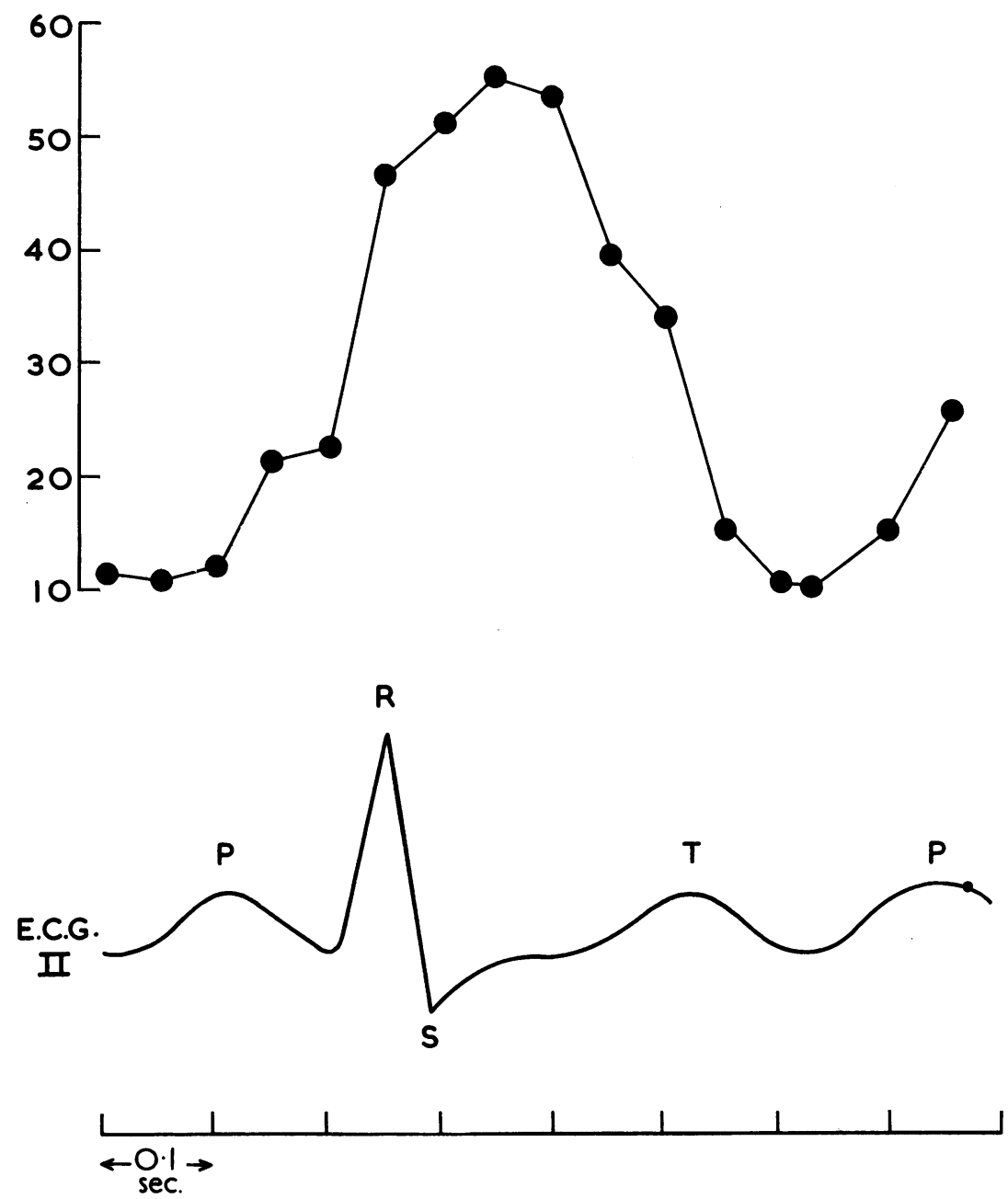

FIG. 3.-Sequential changes of left ventricular cavity area in left lateral cine-angiocardiogram (Case 17), with simultaneous electrocardiogram. Note major increase in left ventricular cavity area during second half of $P$ wave and in end-diastole (including first 0.5 sec. of $Q R S$ ): virtually no ventricular filling before $P$ wave. (Areas in square "units," since measurements made on projected film.)

Left Parasternal Impulse. At the left sternal edge all but 4 of the patients had a normal ventricular systolic impulse and a normal atrial beat also. One showed a sustained ventricular impulse, and 3 a large atrial beat which was of giant size in 2, exceeding $10 \mathrm{~mm}$. in height.

In most patients hæmodynamic disturbances in right ventricular function were relatively slight compared with those in the left ventricle. In one of the two patients, however, with a giant atrial beat at the left sternal edge, the height of the " $a$ " wave and the end-diastolic pressure in the right ventricle were considerably raised and of the same order as those in the left ventricle, being 20 and $8 \mathrm{~mm}$. $\mathrm{Hg}$, respectively (Case 1, Fig. 2b). In the second patient with a giant atrial beat at the left sternal edge, right-sided catheterization was not performed.

\section{CINE-ANGIOCARDIOGRAPHIC STUdIES}

A direct relationship might be expected between evidence of increased atrial transport function and a 


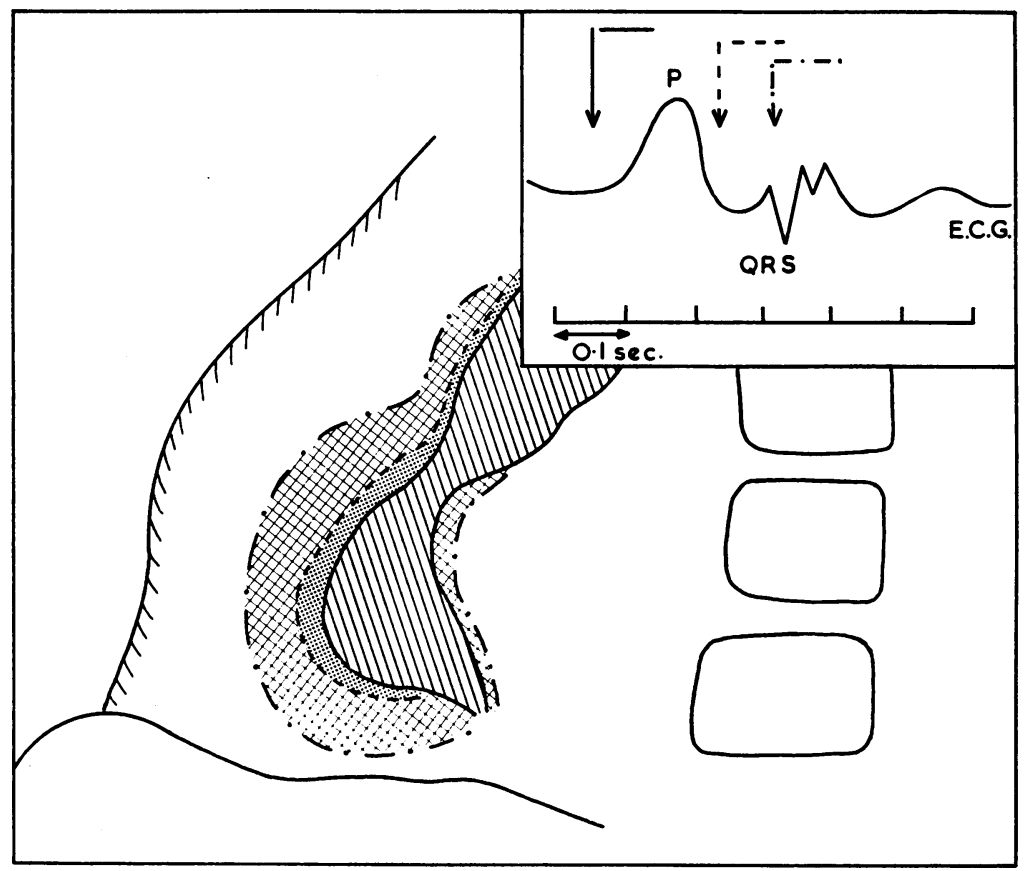

FIG. 4.-Superimposed tracings of cine-angiocardiograms of right ventricle (Case 1), in left lateral view, at three points during cardiac cycle, indicated in simultaneous electrocardiogram. Note major increase of ventricular cavity area during downstroke of $P$ wave $(---$ line $)$ and beginning of $Q R S(-\ldots .-$ line $)$, i.e. in atrial systole and end-diastole.

giant atrial beat in the impulse, since the latter reflects ventricular wall displacement during atrial systole. While pressure records at catheterization provide evidence of diminished ventricular compliance and increased atrial systolic pressure in cardiomyopathy, it is in the cine-angiocardiogram that direct evidence of increased atrial transport function is to be found. Case 17, who showed the largest giant atrial beat in the series, had a left ventricular angiocardiogram suitable for detailed analysis. In Fig. 3 it will be seen that the major increase in cross-sectional area of the left ventricle in the frontal projection did not take place until atrial contraction occurred and the atrium discharged its contents into the ventricle. These changes in cross-sectional area were noted in both the antero-posterior and the lateral view cineangiocardiogram. Since the cine-angiocardiograms were not taken by a bi-plane method, no direct inference could be drawn from them about volume changes in the left ventricular cavity, but they lent support to the concept of increased atrial transport function in ventricular filling in this patient.

Case 1 was a patient who was also of special interest (Table). A giant atrial beat was present at both apex and left parasternal areas. At cardiac catheterization there was evidence of increased atrial systolic pressure and decreased ventricular compliance on both sides of the heart, the pressure in right and left ventricles rising to $20 \mathrm{mg}$. $\mathrm{Hg}$ during atrial systole, with an end-diastolic pressure of $8 \mathrm{~mm}$. $\mathrm{Hg}$, as already described. His rightsided cine-angiocardiogram was studied and showed evidence compatible with increased atrial transport function on the right side of the heart, similar to that shown in Case 17 on the left side of the heart. Fig. 4 shows superimposed outline tracings of the right ventricular cavity in the left lateral view at three points during the cardiac cycle, together with their timing in the simultaneous electrocardiogram. In Fig. 5 the sequential changes in cross-sectional area of the right ventricle in the oblique view are shown throughout diastole, where it is clear that the major increase in area of the right ventricular cavity occurs during atrial systole and end-diastole.

\section{Discussion}

Our study shows that the double apical impulse of cardiomyopathy is usually due to an abnormally large atrial beat, preceding the impulse accompany- 


\section{RV CAVITY AREA}

sq. units

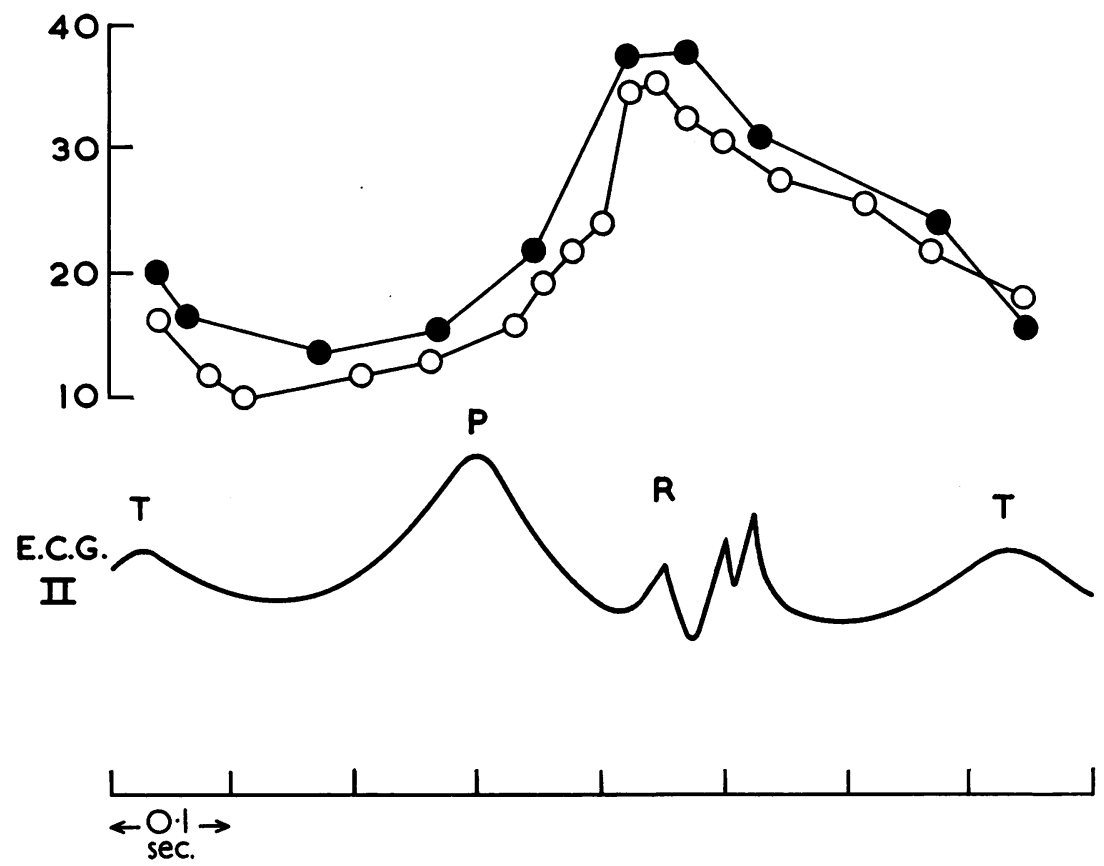

FIG. 5.-Sequential changes of right ventricular cavity area, calculated from cine-angiocardiogram illustrated in Fig. 4 (Case 1). $O=$ in postero-anterior projection; $\Theta=$ left lateral. Analysis of frames, at 0.025 sec. intervals, confirms that major increase in area of ventricular cavity takes place in atrial systole and enddiastole.

ing ventricular systole. It is the very large size of this atrial beat, at times reaching giant proportions and dwarfing the ventricular systolic impulse, that gives it its characteristic quality. A bifid character to the ventricular systolic portion of the impulse was a relatively rare finding and, where present, was always preceded by an atrial beat also.

In some patients the apical impulse of cardiomyopathy did not differ in any major respect from that of left ventricular hypertrophy from other causes, such as hypertension or aortic stenosis, where a large atrial beat is followed by a taller sustained ventricular systolic impulse. Where the atrial beat dwarfs the ventricular beat, or approaches it closely in height, as in 7 of our patients, the diagnosis of cardiomyopathy should be considered on the evidence of the cardiac impulse alone, since this sign is rarely seen in other diseases.

Both the ventricular and the atrial portion of the apical impulse reflect the underlying hæmodynamic abnormalities. A general correlation was noted in our series between a large pressure gradient across the left ventricular outflow tract on the one hand and the sustained nature of the ventricular systolic impulse on the other. This was to be expected in so far as the pressure gradient partly reflected the degree of ventricular hypertrophy, since a sustained cardiac impulse has been shown to be a reliable sign of ventricular hypertrophy (Beilin and Mounsey, 1962). The degree of functional obstruction, however, in this disease is not directly related to over-all ventricular hypertrophy, but rather to the amount of localized hypertrophy in the outflow tract and also to varying myocardial contractility under different physiological conditions (Braunwald and Ebert, 1962; Cohen et al., 1964). For these reasons alone a closer correlation between the pressure gradient and the form of the apical impulse was not to be expected, a number of patients showing a sustained impulse with only a small gradient across the left ventricular outflow tract at the time of catheterization.

Of equal interest, from the hæmodynamic viewpoint, was the frequent finding of a large atrial beat 
in the apical impulse of our patients, an observation previously noted in other series (Mounsey, 1959; Paré et al., 1961; Wigle et al., 1962; Benchimol et al., 1963; Cohen et al., 1964; Gillam et al., 1964; Tafur et al., 1964). This augmented atrial beat of obstructive cardiomyopathy reflects one of the basic hæmodynamic abnormalities of the disease, namely decreased ventricular compliance, with increased atrial systolic pressure and increased atrial transport function. Cine-angiocardiography confirmed the abnormally large outward movement of the ventricular wall during atrial systole, responsible for the large atrial beat on the overlying cardiac impulse.

\section{SUMMARY}

The cardiac impulse has been studied in 14 patients with hypertrophic obstructive cardiomyopathy, using the impulse cardiogram. The diagnosis and extent of the lesion were examined in all cases by cardiac catheterization and angiocardiography.

At the apex, the most characteristic physical sign in the cardiac impulse was an atrial beat of "giant" size, approaching or exceeding the amplitude of the ventricular systolic impulse-a sign that was met in 6 of the 14 patients, and gave a clear "double impulse" on palpation at the bedside. Smaller atrial beats were met in all but one of the other patients.

The apical ventricular systolic impulse was abnormally sustained in 10 patients, with a bifid character in 3: in the remaining 4 patients it was normal.

The large atrial beat reflected increased left atrial transport function, demonstrated on cine-angiocardiography, associated with a raised atrial systolic pressure and decreased ventricular compliance.

A general correlation was found between an abnormally sustained ventricular impulse and the presence of a marked pressure gradient between the hypertrophic left ventricle and the aorta.
With one exception, hæmodynamic disturbances in the right ventricle were slight compared with those in the left, and this accorded well with the normal left parasternal impulse in all but 4 patients.

We would like to thank Professor J. F. Goodwin and Dr. Celia Oakley for allowing us to study patients under their care and Professor R. E. Steiner for his help in the analysis of the angiocardiograms. We are also grateful to Mr. Peter Burgess and Miss Jean Powell for technical assistance.

\section{REFERENCES}

Beilin, L., and Mounsey, P. (1962). The left ventricular impulse in hypertensive heart disease. Brit. Heart $\mathcal{F}$., 24, 409.

Benchimol, A., Legler, J. F., and Dimond, E. G. (1963). The carotid tracing and apex cardiogram in subaortic stenosis and idiopathic myocardial hypertrophy. Amer. F. Cardiol., 11, 427.

Boiteau, G. M., and Allenstein, B. J. (1961). Hypertrophic subaortic stenosis. Clinical and hemodynamic studies with special reference to pulse contour measurement. Amer. F. Cardiol., 8, 614.

Braunwald, E., and Ebert, P. A. (1962). Hemodynamic alterations in idiopathic hypertrophic subaortic stenosis induced by sympathomimetic drugs. Amer.F. Cardiol., 10, 489 .

-, Morrow, A. G., Cornell, W. P., Aygen, M. M., and Hilbish, T. F. (1960). Idiopathic hypertrophic subaortic stenosis; clinical, hemodynamic and angiographic manifestations. Amer. F. Med., 29, 924.

Cohen, J., Effat, H., Goodwin, J. F., Oakley, C. M., and Steiner, R. E. (1964). Hypertrophic obstructive cardiomyopathy. Brit. Heart $\mathcal{F}_{\text {., 26, } 16 .}$

Deliyannis, A. A., Gillan, P. M. S., Mounsey, J. P. D., and Steiner, R. E. (1964). The cardiac impulse and the motion of the heart. Brit. Heart f., 26, 396.

Gillam, P. M. S., Deliyannis, A. A., and Mounsey, J. P. D. (1964). The left parasternal impulse. Brit. Heart $\mathcal{F}$., 26, 726 .

Mounsey, P. (1959). Præcordial pulsations in relation to cardiac movement and sounds. Brit. Heart $\mathcal{F}$., 21, 457.

Pare, J. A. P., Fraser, R. G., Pirozynski, W. J., Shanks, J. A., and Stubington, D. (1961). Hereditary cardiovascular dysplasia. A form of cardiomyopathy. Amer. $\mathcal{F}$. Med., 31, 37.

Tafur, E., Cohen, L. S., and Levine, H. D. (1964). The apex cardiogram in left ventricular outflow tract obstruction. Circulation, 30, 392.

Wigle, E. D., Heimbecker, R. O., and Gunton, R. W. (1962). Idiopathic ventricular septal hypertrophy causing muscular subaortic stenosis. Circulation, 26, 325. 